\title{
Analyzing Methods of Using Sustainable Development Indicators
}

\author{
Fani Samara, Olga Christopoulou and Athanasios Sfougaris \\ Department of Planning and Regional Development, University of Thessaly, Volos 38334, Greece
}

\begin{abstract}
Sustainable development indicators, aim to measure sustainable development over longer periods of time. The sustainable development indicators are grouped into 10 subject categories: socioeconomic development, sustainable consumption and production, social inclusion, demographic changes, public health, climate change and energy, sustainable transport, natural resources, global partnership and finally good governance. In this paper, the authors examined a number of researches and compared the methods they used in order to determine the advantages and disadvantages of each method. The methods used a large number of different indicators. The comparison of the indicators could be made through mathematical models and also through theoretical approach.
\end{abstract}

Key words: Sustainable development indicators, methodology, urban planning.

\section{Introduction}

In Chapter 40 of Agenda 21, the development of indicators for sustainable development is called for. In particular, countries at the national level, international governmental and non-governmental organizations at the international level are requested to develop the concept of indicators of sustainable development in order to identify such indicators. This issue was raised during the first two sessions of the CSD (Commission on Sustainable Development), at which time a large number of countries emphasized the urgent need for these indicators. Other countries expressed some concern and insisted that indicators would be developed in cooperation with governments. Pursuant to the schedule adopted by the commission at its first session, the progress achieved on developing these indicators, in the context of Chapter 40 of Agenda 21, will be discussed by the commission during its third session. The objective of this schedule is primarily to make the indicators for sustainable development accessible to decision-makers, at the national level, by defining them, elucidating their methodologies and

Corresponding author: Fani Samara, engineer, research fields: regional planning and sustainable development. E-mail: fanisamara@gmail.com. providing training and other capacity-building activities. Indicators, used in national policies, may also be used in the national reports of the CSD and other intergovernmental bodies [1].

A large number of researches have been taken place in the entire world about the sustainable development indicators. A lot of researchers use the analytic network process for criteria selection which is the most widespread nowadays. Multi criteria analysis methods can help to optimize the power of criteria and indicator approach to have a comprehensive analysis for sustainable development. Also, another method which uses a lot of researchers is the GIS and the multi-criteria decision analysis. Through GIS could construct clusters and rasters and finally compare the results for choosing the best scenario [2].

\section{Methodology}

In this paper, a number of researchers and methods were analyzed and compared with four case studies. Specifically, the first case study has been talked in the paper "analyzing the role of sustainable development indicators in accounting for and constructing a sustainable Scotland” [3]. The second case study has been discussed in the paper "a method to assess the 
relevance of sustainability indicators: Application to the indicator set of the Czech Republic's Sustainable Development Strategy" [4]. The third case study has been given in the paper "environment and sustainable development indicators in Lebanon: A practical municipal level approach" [5], and the fourth case study has been talked in the paper "perspectives of sustainable development in countries of southeastern Europe" [6].

\subsection{Case Study I}

The first case study has been talked in the paper "analyzing the role of sustainable development indicators in accounting for and constructing a sustainable Scotland".

The main objective of the above paper was to analyze the impact of sustainable development indicators on the integration of sustainable development into the governing of Scotland. A major concern was whether an accounting technology could represent this complex multi-dimensional and interdisciplinary concept. They analyzed the relationship between the official sustainable development strategy of the Scottish Executive and the associated indicator set using an analytics of government framework. They observed a lack of alignment between these sustainable development indicators and the visions, fields of visibilities, forms of knowledge and techniques of government contained in this strategy.

The empirical evidence used in this paper was drawn from a wider longitudinal analysis where they applied the analytics of government framework to a number of key strategic data and sustainable development indicators reports produced by the Scottish Executive. This paper was based upon a critical reading of "Choosing Our Future" and related documents and websites. "Choosing Our Future" was chosen to be the focus of this paper because it was the most comprehensive of all the sustainable development strategies.
The documents were analyzed in four stages: First, a cognitive map of the content of each document was created; Second, these individual maps were reviewed to derive a common cognitive mapping structure and each document was remapped using this common structure; Third, the maps were represented using key elements of the analytics of government framework. These elements were: the objective and vision of the document, problematisations contained within, fields of visibility, techniques of government, forms of knowledge and identity formation; Fourth, these revised maps were overlaid and interpreted using the characterization of practices and rationalities of government.

In the research a multilayered analytical framework has been used and this section will be structured according to these different layers. The analysis and evaluation of the data is presented as follows: Firstly, the analysis of the sustainable vision, problems and actions of Choosing Our Future has been presented; Secondly, the analysis of vision, visibilities and dividing practices of the sustainable development indicators has been presented; Thirdly, the alignment of forms of knowledge in Choosing Our Future and the sustainable development indicators have been analyzed; Fourthly, the alignment between the sustainable development indicators and Choosing Our Future's technologies of government has been analyzed; Finally, the summary of the different layers of analysis has been presented.

The paper was motivated by the possibility that sustainable development indicators could negatively impact upon the integration of sustainable development into the everyday governing of Scotland. A major concern was the effectiveness of accounting technologies on representing this complex multi-dimensional and interdisciplinary concept. These concerns were grounded in findings from prior research into social and environmental accounting, sustainable development indicators and govern mentality studies of accountancy [3]. 


\subsection{Case Study II}

The second case study has been discussed in the paper "a method to assess the relevance of sustainability indicators: Application to the indicator set of the Czech Republic's Sustainable Development Strategy".

The goal of this article is to critically review the state-of-the-art in assessing the quality of sustainability indicators and contribute to the development of a suitable methodology for that. They start with a broad review of a vast body of work in this field-in both practice and academic research. They show that both scientists and practitioners have sought developing and using methods for assessing quality of the indicators. They have usually defined some criteria for that, however, neither science nor practitioners provided major support by developing reliable as well as practical and operative methods for indicator assessment. Therefore, they propose an innovative new method for indicator assessment from the perspective of their relevance. They operationalize this criterion and apply it to the environment-related indicators from the set used for the evaluation of the Czech Republic's Sustainable Development Strategy.

In this context, by success they mean massive spread, frequent use and high popularity. Therefore, they delimited the domain of their interest to providing a method (tool) for indicator developers and users so that they can readily identify what is pertinent and what is not. They narrowed the wide choice and potential application of the assessment criteria down to one of them: relevance. In accordance with the findings of the literature survey shown in the previous sections, they started with a notion that relevance is a term used to describe how pertinent, connected or applicable something is to the indicators.

The criteria and the indicators used in this research are public transport (transport intensity), use of energy (energy intensity, primary energy supply, share of renewable energy), climate change (greenhouse gas emission per capita, greenhouse gas emissions per
GDP), use of resources (material consumption), waste treatment (material use of waste), agriculture (consumption of mineral fertilizers, consumption of pesticides, organic farming), forestry (defoliation), biodiversity (bird index) and environmental protection (expenditures on environmental protection).

There has been no agreement or consensus on a common set of scientific and management criteria for evaluating or assessing indicators from several points of view. The results of the assessment were statistically processed and discussed. The discussion investigated the suitability of the proposed procedure and the recommendations stemming from the experimental assessment conducted for further work on the progress reports [4].

\subsection{Case Study III}

The third case study has been given in the paper "environment and sustainable development indicators in Lebanon: A practical municipal level approach”.

In close coordination and collaboration with the Lebanese Environment and Development Observatory at the Ministry of Environment, the Faculty of Health Science at the University of Balam developed an action plan to "establish a decentralized environment and sustainable development monitoring network through local authorities using agreed upon environment and development indicators”. This effort was part of a pilot regional project involving six Mediterranean countries with funds provided by the Ministry of Environment, Greece through the University of Athens to establish a "Mediterranean Environmental Reporting, Monitoring and Information System" for Mediterranean countries. According to a well-defined selection process, a total of 44 municipalities out of more than 700 municipalities belonging to three unions representing three different regions in Lebanon qualified for inclusion in the project with 17 choosing to participate in MED-ERMIS-Lebanon. Meetings with concerned public officials at all levels were then held to ensure the support of all relevant governmental institutions and 
therefore the success of the project. Applying a participatory approach, local government officers and representatives from relevant ministries, universities, research centers and non-governmental organizations were invited to attend the different workshops at the municipality level to produce the appropriate lists of indicators. A total of 110 indicators were generated and grouped into four major categories adopted by the national indicator system: (1) population and socio-economic; (2) economic activities; (3) environment; (4) sustainable development activities and policies. "Indicator data sheets", a "door-to-door questionnaire" and a "municipality archive survey" were developed for data compilation, calculation and presentation, and a total of 6,250 questionnaires were filled (20\%). Field surveying was carried out by trained teams using the "Multistage Cluster Systematic Random Sampling” technique and data analysis. Data is being currently interpreted, and a user friendly software application hosted on the University of Balam and web-site to facilitate the updating of indicators and the dissemination of indicator data on the World Wide Web has been developed allowing access to information by all interested parties [5].

\subsection{Case Study IV}

The fourth case study has been talked in the paper "perspectives of sustainable development in countries of Southeastern Europe".

Countries of SE Europe are at the very beginning of planning their development in accordance with theoretical concept of sustainable development. Sustainable development is defined as the basic imperative and the only model of development in a longer period of time. The basic indicators of sustainable development represent a very useful and qualitative way for measuring and monitoring the state of sustainable development, as in every country individually as well as in the regions and globally as a whole. Values of the indicators of all four subsystems in observed countries are within expectation. Also the current level of development of every country separately is taken into account and in accordance to that, it the current position of any country in respect to its international requests is defined. The special value results from the comparison of obtained results of the state in the developed EU countries, according to which there is an impression of equal level of sustainable development in France and Germany. Whereas, the data regarding the level of sustainable development in Greece and Slovenia has been improved between two analysis. Taking into account the results of the previous and current research there is a clear need for regular observation of every indicator individually but also the need to observe the relationship among them as a whole. Special attention needs to be paid to the intensive monitoring of indicators of economic and ecological subsystem. The research showed, among other things, the fragile relationship between values of indicators of economic and ecological subsystem, so that any change in values of one indicator consequently leads to changes in the final result. Both conducted researches point to the fact that the value of the mentioned indicators changes at the fastest pace [6].

\section{Discussion}

A different model was used in each described method. Table 1 presents a comparison of used methodologies.

In the first case study, the researchers used the longitudinal method. One of the advantages of this research is that this program is a governmental program, so there are a lot of data and collaboration between the organizations. Also, the researchers collected data, every year, so they can compare their results. On the

Table 1 A comparison of used methodologies.

\begin{tabular}{ll}
\hline Case studies & Methods \\
\hline Case study I & Longitudinal analysis \\
Case study II & $\begin{array}{l}\text { Practice and academic research } \\
\text { Indicator data sheets }\end{array}$ \\
Case study III & $\begin{array}{l}\text { Door to door questionnaire } \\
\text { Municipality archive survey } \\
\text { Comparison between developed and } \\
\text { Case study IV }\end{array}$ \\
\hline
\end{tabular}


other hand, despite the containing number of radical elements there is a lack of an overarching concise conceptual definition of sustainable development in the program Choosing Our Future.

In the second case study, the researchers present a practice and an academic research. The advantages of this research are that they used keywords for analyzing the results, so they can compare them. Also, they distinguish between the relevance of the theme of an indicator and the relevance of the indicator itself for the theme. Moreover, they made a pretest research. However, besides lack of operationalization of the validation criteria, another weakness of the indicator assessment methods proposed so far has been the fact that they have often been qualitatively based on expert evaluation which hampered their reproducibility.

In the third case study, the research is part of a pilot regional project involving six Mediterranean countries. Also, there is collaboration between the organizations and the Ministry of the Environment. Moreover, the collection of the random sampling was different for each method. In addition, this research would allow the municipalities to contribute the compiled indicator data to the database of the Ministry of Environment in the future. However, there are some difficulties to the research, for example, Lebanon lacked baseline data, both on the national and local scales and decisions are taken based on either outdated or erroneous baseline information. Nevertheless, community-based projects, more specifically those introducing new methodologies for planning and development, encounter resistance and challenges from stakeholders. Difficulties were encountered in obtaining clear commitments from stakeholders in relation to attendance, participation and involvement, mostly due to the lack of knowledge about indicator science, limited resources and the concern of the level of work that needs to be undertaken. In addition, the absence of the culture of indicators exacerbated by the lack of baseline data has also led to drawbacks in the surveying method ranging from securing the needed percentage of respondents to the absence of archival data, to the disinterest by municipal employees in providing the available data for the municipal archive survey.

In the fourth case study, the goal of the research was the comparison between developed and undeveloped countries. In order to provide more precise results the weight coefficients in range from 0 to 100 were used. Also, this research used new values of indicators, but the methodological approach was the same as the one used in a previous research in 2006. The results of research in the countries of Southeastern Europe, and their comparison with the state of indicators in Germany and France lead to significant conclusions. However, the research that dealt with the similar problem (monitoring, comparison and determining the degree of importance of chosen indicators of sustainable development in countries of Southeastern Europe) has been performed by the authors at 2006. In that way, the authors were able to conduct a comparison with the previous results. The researches that deal with the comparison of the overall state of sustainable development in countries of Southeastern Europe with some of the most developed countries of the European Union have not been found either, so the authors used only their research results for comparison [7].

\section{Conclusions}

In above articles, a different method is used as they aim for a different goal. Also, in the paper different approaches of the indicators due to the level of development of the case study country were presented. Additionally, observe that the countries with higher economic growth use more complex methods and indicators than the less economic developed countries. Moreover, the researches which use a mathematical model can calculate more complex indicators. In the other side, the researches which have used questionnaires and data collection are more representative.

All methods need data collection that is one of the 
most difficult parts of each research. Also, the four models use different criteria as well as indicators.

In this paper, the authors compare different methods about the indicators and criteria. The goal of the paper was to create a new model which will take place in Greece. In the new model which would be constructed the collection of the data would be made through questionnaires and statistics data from the Ministry of Economics. Also, the indicators would be separated in three categories (economic, environmental and demographical). Moreover, the results of the research would be set in maps through graphs so that the comparison would be easier. Finally, with the help of GIS raster images will be constructed.

\section{Acknowledgments}

This research has been cofinanced by the European Union (ESF (European Social Fund)) and Greek national funds through the Operational Program "Education and Lifelong Learning" of the NSRF (National Strategic Reference Framework)-Research Funding Program: THALES. Investing in knowledge society through the European Social Fund.

\section{References}

[1] M. Golusin, O. MunitlakIvanovic, Definition, characteristics and state of the indicators of sustainable development in countries of Southeastern Europe, Agriculture, Ecosystems and Environment 130 (2009) 67-74.

[2] C.C. Boggia, Measuring sustainable development using a multi-criteria model: A case study, Journal of Environmental Management 91 (2010) 2301-2306.

[3] S. Russell, I. Thomson, Analysing the role of sustainable development indicators in accounting for and constructing a sustainable Scotland, Accounting Forum 33 (2009) 225-244.

[4] T. Hak, J. Kovanda, J. Weinzettel, A method to assess the relevance of sustainability indicators: Application to the indicator set of the Czech Republic's sustainable development strategy, Ecological Indicators 17 (2012) 46-57.

[5] M. Nader, B. Salloum, N. Karam, Environment and sustainable development indicators in Lebanon: A practical municipal level approach, Ecological Indicators 8 (2008) 771-777.

[6] O. MunitlakIvanovic, M. Golusin, S. Dodic, J. Dodic, Perspectives of sustainable development in countries of southeastern Europe, Renewable and Sustainable Energy Reviews 13 (2009) 2079-2087.

[7] J. Wilson, P. Tyedmers, R. Pelot, Contrasting and comparing sustainable development indicator metrics, Ecological Indicators 7 (2007) 299-314. 